\title{
110. Geophysical Significance of the Areal Deformation of the Base Line Rhombus at Mitaka.
}

\author{
By Chûji Tsubor.
}

Earthquake Research Institute, Tokyo Imperial University.

(Rec. Nov. 10, 1930. Comm. by T. Terada, M.I.A., Nov. 12, 1930.)

There is a special set of geodetic base lines in the compound of the Tokyo Astronomical Observatory at Mitaka. They form a rhombus whose four sides as well as one of the diagonals NS are $100 \mathrm{~m}$. long. In the interval of 12 years from 1916 to 1927 , the lengths of the lateral sides and the diagonal NS of the rhombus were measured 15 times with the accuracy up to $0.01 \mathrm{~mm}$. by the hands of the experts of the Land Survey Department of the Imperial Army under the supervision of the Imperial Japanese Geodetic Commission." It was found that these lengths Fig. 1. did not remain exactly constant but

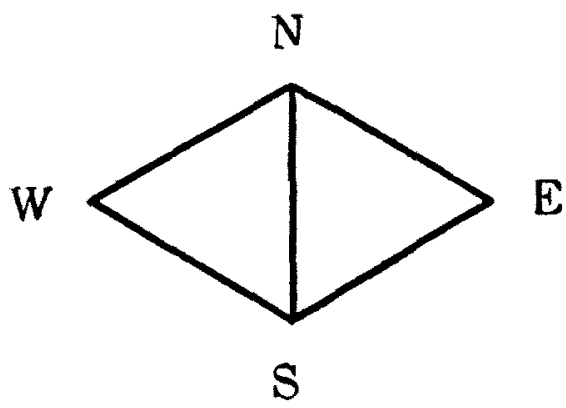
were subject to small variations between two successive measurements which were usually less than $0.5 \mathrm{~mm}$. An abnormally large elongation occurred at the time of the great Kwanto earthquake of 1923 in the length of the diagonal NS which was as much as $3.54 \mathrm{~mm}$.

From these data of the variation in the lengths of the sides of the rhombus, we can calculate the variation in the areas of the triangles NWS and NES in the following way.

The area $S$ of a triangle is given by

$$
S=\sqrt{s(s-a)(s-b)(s-c)},
$$

where $s$ is half the sum of the sides of the triangle. In the present case, $a=b=c=100^{m}$, therefore $\frac{d S}{S}=\frac{1}{2}\left\{\frac{2 s-a}{s(s-a)}\right\} d s=\frac{d s}{75000}, \quad d s$ being measured in $\mathrm{mm}$. According to this relation, the areal divergences $\frac{d S}{S}$ were calculated. The results of the calculation are shown in the following table.

1) T. Umemoto: Astro. Herald, 21 (1928), 127. 


\section{TABLE I.}

\begin{tabular}{|c|c|c|c|c|}
\hline \multirow{2}{*}{ Date } & \multicolumn{2}{|c|}{$\frac{d S}{S}$ for $\triangle \mathrm{NES}$} & \multicolumn{2}{|c|}{$\frac{d S}{S}$ for $\triangle S W N$} \\
\hline & & Integrated & & Integrated \\
\hline $\begin{array}{l}1916 \text { June } \\
1917 \text { Feb. } \\
1917 \text { Oct. } \\
1918 \text { Feb. } \\
1918 \text { Oct. } \\
1919 \text { Nov. } \\
1920 \text { Nov. } \\
1921 \text { Nov. } \\
1922 \text { Nov. } \\
1923 \text { Sept. } \\
1923 \text { Oct. } \\
1924 \text { Jan. } \\
1924 \text { Aug. } \\
1925 \text { Dec. } \\
1927 \text { Dec. }\end{array}$ & $\begin{array}{l}-0.04 \times 10^{-5} \\
+0.55 \\
-0.56 \\
-0.41 \\
+0.73 \\
+0.32 \\
+0.05 \\
-0.26 \\
+2.87 \\
-0.46 \\
-0.14 \\
-0.53 \\
+0.55 \\
+0.87\end{array}$ & $\begin{array}{l}-0.04 \times 10^{-5} \\
+0.51 \\
-0.05 \\
-0.46 \\
+0.27 \\
+0.59 \\
+0.64 \\
+0.38 \\
+3.25 \\
+2.79 \\
+2.65 \\
+2.12 \\
+2.67 \\
+3.54\end{array}$ & $\begin{array}{l}-0.05 \times 10^{-5} \\
+0.50 \\
-1.03 \\
+0.49 \\
+0.31 \\
+0.34 \\
+0.14 \\
-0.17 \\
+2.64 \\
-0.29 \\
-0.37 \\
-0.16 \\
+0.21 \\
+1.00\end{array}$ & $\begin{array}{l}-0.05 \times 10^{-5} \\
+0.45 \\
-0.58 \\
-0.09 \\
+0.22 \\
+0.56 \\
+0.70 \\
+0.53 \\
+3.17 \\
+2.88 \\
+2.51 \\
+2.35 \\
+2.56 \\
+3.56\end{array}$ \\
\hline
\end{tabular}

The values of $\frac{d S}{S}$ calculated for the different triangles NES and SWN are closely coincident with each other which fact is a clear indication that the areal deformations of the two triangles as calculated in the above were really produced by the general deformation of the surrounding earth's crust but were not apparent ones produced merely by the accidental displacements of one or some of the base stones at the ends of the base lines.
Fig. 2.

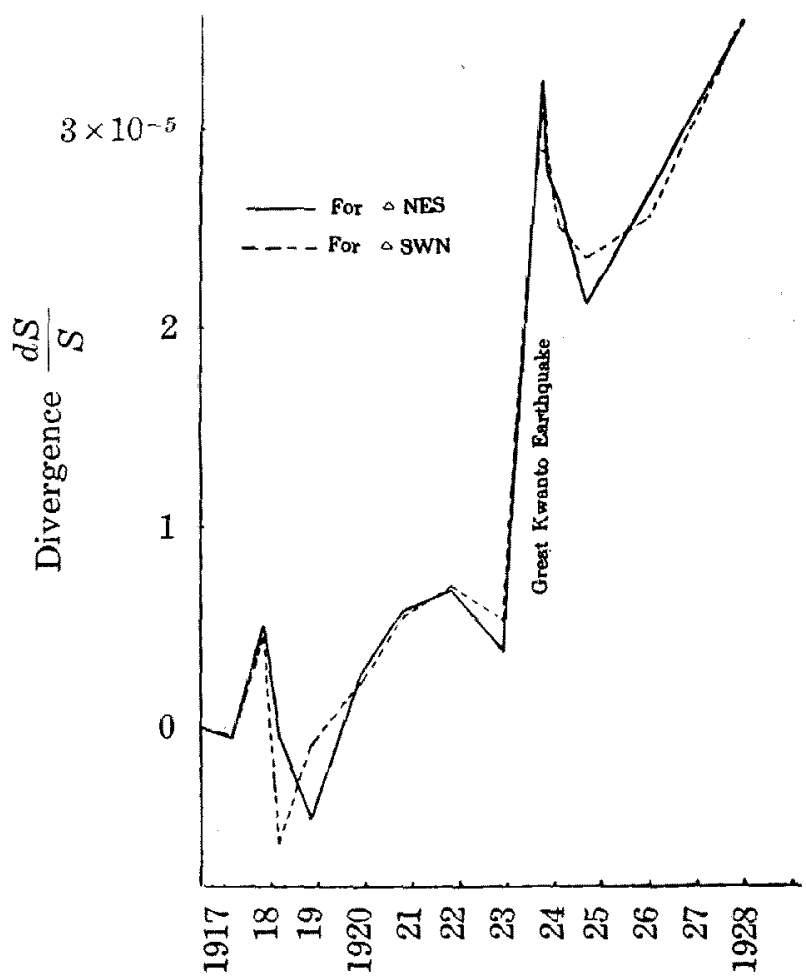


No. 9.] Geophysical Significance of the Areal Deformation of the Base Line. 369

The curves in Fig. 2 show the integrated areal divergences of the two triangles. It will be seen that the areas of the triangles have been continuously expanding with the episode of the great earthquake of 1923 which disturbed the general course of their expansions. It seems that before the event of the earthquake of 1923, the general areal expansion was somewhat hindered in its course while after that it restored its original course from the point corresponding to a too much expansion.

At the time of the great earthquake of 1923, the divergences of the triangles were $2.9 \times 10^{-5}$ for NES and $2.6 \times 10^{-5}$ for SWN. It may be of special interest to note that the divergence of the smallest geodetic triangle including the Mitaka region calculated after 'Terada's method ${ }^{1)}$ by the comparison of the triangulations before and after the earthquake comes out to be $4.5 \times 10^{-5}$. This value is larger than that obtained for the small triangles of the rhombus. But this inconsistency would seem to be rather reasonable both in sense and magnitude, if we consider that the Mitaka region has been gradually

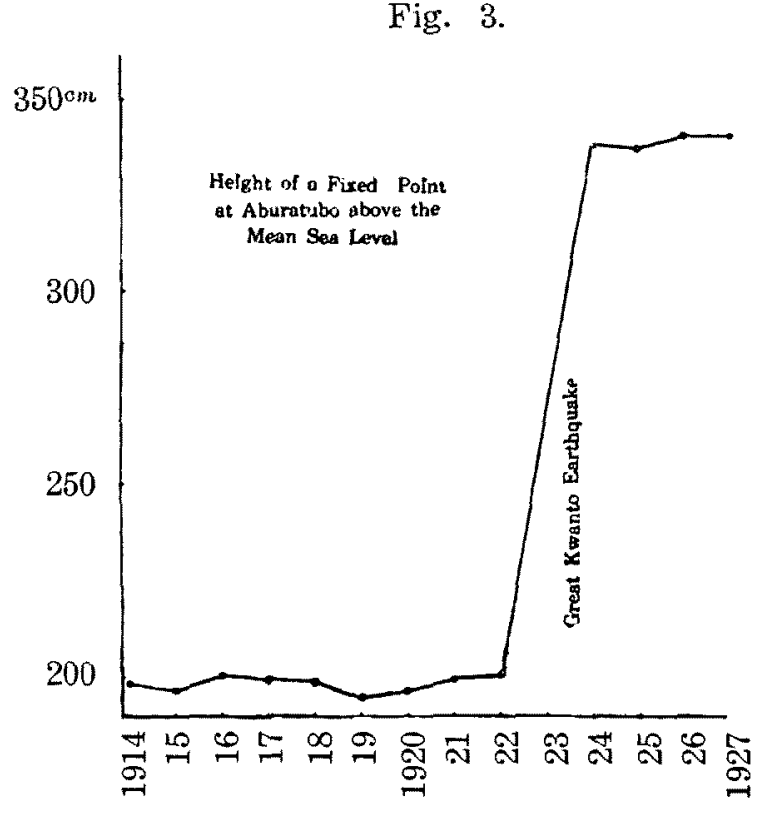
expanding in its area recently and the comparison of the triangulations was made between the new and old data with an interval of some 30 years.

It is worth of special mention that the curves of the changes of areas of the triangles of the rhombus are fairly similar in their forms with the curve of the change of height above the mean sea level of the bench mark at Aburatubo which is a mareographic station nearest to the epicentre of the great earthquake of 1923. This fact suggests that there was some physical connection in the

1) T. Terada and N. Miyabe: Bull. Earthq. Res. Inst., 7 (1929), 223. 
mechanisms of producing the areal deformation at the Mitaka region on the one hand and the vertical displacements at Aburatubo on the other hand.

In conclusion, the writer wishes to express his best thanks to Professor T. Terada for his interests in this work. 